\title{
Utilization and Accessibility of Social Services for Chinese Canadians
}

\author{
Ambrose Ma, Ph.D. \\ and \\ Iris Chi, D.S.W. \\ Department of Social Work and Social Administration \\ The University of Hong Kong \\ Room 1326, K.K. Leung Building \\ Pokfulam Road \\ Hong Kong \\ Tel: (852) 2859-2067 \\ E-mail: amma@hkucc.hku.hk
}

October 2003 


\title{
Utilization and Accessibility of Social Services for Chinese Canadians
}

\author{
Abstract \\ The findings show that the awareness of service agencies and opinions on the services \\ provided are predictors of Chinese-Canadians' service utilization, and that one-third of Chinese- \\ Canadians have not used any social services, for various reasons. When planning services for an \\ ethnic minority group like Chinese-Canadians, planners should consider socio-cultural and \\ structural factors alike.
}


Since the late 1980s, the number of Chinese Canadians in large Canadian cities has been increasing steadily. Now, this is the fastest growing ethnic minority group and their language is the second most widely-used in Canada. In order to help this group settle in the country and adapt to Canadian society, social service agencies serving these new Chinese immigrants have conventionally provided a variety of services to those in need.

In recent years however, in response to various fiscal constraints, these agencies have had to take positive measures to enhance the accessibility and cost-efficiency of their programs. To achieve these objectives, a thorough understanding of the use of and barriers to the provision of social services for these Chinese Canadians is crucial.

Unfortunately, there is a lack of reliable information about Chinese Canadians' perception of the social services available to them and the way in which they seek help. Scientific study of these areas will definitely increase the body of knowledge on Chinese Canadians' use of these services and will shed light on the options available for service planning and provision.

\section{Previous Studies}

Numerous studies have been conducted with the aim of addressing issues related to the utilization of human services. Many of these studies concentrate on the use of health services (Bass et al., 1992; Biegel et al., 1997; Lum \& Chang, 2000; Wolinsky \& Johnson, 1991). Others focus on the behavior of elderly people seeking social services (Carlton-LaNey, 1991; Miner et. al., 1993; Slivinske et al., 1994; Wallace, 1994).

In addition, other academics have devoted a great deal of effort to examining the relationship between ethnicity and service utilization. Many of these studies have reported that in general, compared with Caucasians, immigrants of ethnic minorities under-utilize health services 
(Biegel et al., 1997; Damron-Rodriguez et al., 1994; Snowden \& Cheung, 1990; Sue et. al., 1991). This under-utilization is almost certainly due to a number of barriers: language problems, financial hardships, lack of awareness and acceptability of available services, and attitudes toward using formal support services (Damron-Rodriguez, et al., 1994; Moon et al., 1998; Sowers \& Siddharthan, 1992; Tang, 1996; Ying \& Miller, 1992).

Although previous studies have added to the body of knowledge on service utilization among ethnic minorities, only a limited number of these studies have investigated the utilization of social services (e.g., O'Donnell \& Giovannoni, 1999; Paulino, 1998). Many studies have restricted themselves to services offered by non-culturally-specific organizations, and a few studies compare the characteristics of users and non-users of services (e.g., Auslander \& Lutwin, 1990; Starrett et al., 1992). Furthermore, there is a scarcity of relevant data regarding Chinese immigrants' helpseeking behavior in Canada (Kuo \& Torres-Gil, 2001; Tang, 1996; Tanjasiri et al., 1995; Tsai \& Lopez, 1997). In view of these limitations, the present study has been initiated to fill the knowledge gap in these areas.

\section{The Present Study}

The present study seeks to examine the behavior of Chinese Canadians when seeking help and the barriers to available formal services which currently exist. This study differs from previous studies in three respects, listed below.

First, this study focuses on assessing the utilization of social services rather than health services among Chinese Canadians. The use of social services results in more labeling effects on service users when compared to health services; as social service utilization is more of a reflection of the cultural differences among service users (Keller et al, 1997; Moon \& Villa, 1998). As such, 
the findings of the present study will enrich the body of knowledge on human service utilization. This study also investigates the existing barriers to culturally-appropriate social services provided by Chinese-specific service agencies in Canada's multicultural society; the findings will provide some insight on enhancing the accessibility of social services to Chinese Canadians. Lastly, this study compares the personal characteristics of users of social services with those of non-users among the Chinese Canadian population. Based on the results of this comparison, constructive ideas will be conceived to improve the appropriateness and acceptability of the available social services.

\section{Methods}

This study is based on data derived from a survey of Chinese Canadians' perceptions of community and social services conducted in Toronto, Ontario, Canada (Ma, 1996). The research methods of this study are delineated as follows:

\section{Sample and Data Collection}

The universe of this study was Chinese Canadians aged 18 and above residing in the Greater Toronto Area. The elements to be observed were randomly drawn from common Chinese family names listed in the telephone directory for 1996-97. Telephone interviews were used to collect data from the respondents, as this was the most cost-efficient method of gathering information from Canada. Another reason for the use of telephone interviews was the high telephone subscription rate and relatively low concentration of households in the Greater Toronto Area. The data were collected by trained interviewers in early August 1996. More than 280 interviews were successfully completed, with a response rate of approximately 25 percent (283 out 
of 1,148). However, four questionnaires were later found to be invalid, and thus only 279 questionnaires were used in the analysis.

\section{Measurement}

The variable social service utilization was assessed using an index derived from the aggregate scores of 10 questions. The questions asked the respondents if they had used any of the most common social services available to the Chinese Canadian community, namely: child care, community education workshops, career counseling services, English as a Second Language programs, health promotion programs, home support services, information and referral services, legal aid, programs for new arrivals and services for seniors. Awareness of social service agencies was measured with an additive index derived from the summated scores of seven questions. These questions were related to the awareness of seven prominent Chinese-specific service agencies. Opinions on social services was gauged by the interviewees' responses to five statements pertaining to the importance of and contributions made by social services in terms of enhancing social stability and helping Chinese Canadians adjust to Canadian society. Finally, the variable ability to differentiate social services from basic social security programs was assessed with an additive index derived from three ‘true or false' questions pertaining to both social services and basic social security programs.

\section{Results}

In this study, both descriptive statistical methods and multiple regression were used to analyze the data. The results of statistical analyses are discussed as follows: 


\section{Profile of Respondents}

The findings show that the respondents were quite young, with a mean age range between 30 and 39. The genders were more or less equally distributed. Their education level was fairly high - forty percent of them had completed a high school education, and a similar percentage had attained university or post-secondary education. An overwhelming majority came from Hong Kong (73\%) and a significant minority came from Mainland China (15\%). The rest came from Indo-China (5\%), Taiwan (4\%), and other parts of the world (3\%). Moreover, nearly sixty percent of the respondents had been in Canada for less than 10 years, and twenty-seven percent of them had stayed in the country for 10 to 19 years. The rest (15\%) were 'old-timers', people who had resided in Canada for more than twenty years.

(Table 1 about here)

\section{Predictors of Service Utilization}

Using hierarchical regression analysis, two models were formulated to assess social service utilization among Chinese Canadians. The findings of these analyses are shown in Table 2.

Model 1 was used to examine the relationships between the subjects's socio-demographic characteristics and their use of social services. Among all four socio-demographic characteristics, only education level was significantly - but inversely - correlated with the use of social services. In other words, the higher the level of schooling the people received, the smaller number of social services they tended to use. In this model, the socio-demographic characteristics of Chinese Canadians accounted for only a small portion of the variance $\left(R^{2}=.024\right)$ in service utilization among them. This finding suggests that Chinese Canadians' use of social services is slightly 
affected by their socio-demographic characteristics, and also confirms the results reported in previous studies (e.g., Andersen and Newman, 1973; Ying and Miller, 1992).

In addition to socio-demographic characteristics, awareness of service agencies, opinions on social services, and ability to differentiate social services from social security programs, were included in Model 2 for regression analysis. In this model, the effect of education level decreased slightly, while the other socio-demographic characteristics still had no significant relationship with the subjects' service utilization. The reduced effect of their education level on their use of social services was probably due to the significant inter-correlation between the level of education and Chinese Canadians' opinions on social services.

Of the three facilitating factors, only awareness of service agencies and opinions on social services were highly associated with service utilization among the subjects. Specifically, Chinese Canadians would increase their use of social services if they were more aware of the existence of Chinese-specific service agencies, and if they held a more positive opinion of the services provided by these agencies. The total effect of this model on Chinese Canadians' service utilization was increased by more than three times that of Model $1\left(R^{2}=.106 ; R^{2}\right.$ change $\left.=.082\right)$. Here, the evidence indicates that use of social services among Chinese Canadians is strongly determined by their awareness of available services and positive attitudes toward these services.

(Table 2 about here)

\section{Barriers to Social Services}

The results of descriptive statistics show that 67 percent of Chinese Canadians had used at least one type of social service. However, 33 percent had not used any of the available 
services, due to various reasons. Surprisingly, slightly more than one-third of these non-users (35\%) complained about some structural barriers to such services. These complaints included: a lack of knowledge of available social services (14.3\%), that it was difficult to access the social service agencies (7.7\%), complicated application procedures (5.5\%), the unavailability of services needed (4.3\%), and long waiting list (3.3\%). Another one-fifth of them (20.9\%) needed such services, but wanted to solve their problems by themselves. The rest of these non-users (43.9\%) expressed that they did not need any such services. These findings indicate that a considerable number of Chinese Canadians (11.5\% or 32/279) could not obtain the formal help they needed, though a significant minority (21.1\% or 59/279) were relatively independent of the available services.

(Table 3 about here)

\section{Comparison between Service Users and Non-users}

In order to examine the factors influencing the help-seeking behavior of these non-users, Mean and ANOVA were used to compare the personal characteristics of the service users with those of the three groups of non-users. The results of these analyses are summarized in Table 4.

In general, the service users were different from the non-users in their education level, length of residency, awareness of service agencies, and sex ratio. Compared to the service users, those subjects who had no need for the available services were more educated ( $p<.001)$, but less aware of the existence of the service agencies $(p<.003)$, and had more males among them $(p$ $<$.094). Those non-users who wanted to solve problems by themselves had a longer residency period $(p<.004)$ and a higher sex ratio $(p<.061)$, but were less familiar with the service 
agencies $(p<.068)$, in comparison with the service users. These findings suggest that being more educated and living for a longer period in the host society - indirect indicators of personal competence and knowledge of community resources - could strengthen ethnic minority immigrants' self-reliance and speed up the process of their acculturation. Since the non-users did not rely on formal services, they tended not to pay much attention to the available social services.

Unlike the aforementioned non-users, those non-users who encountered structural barriers to Chinese-specific services appeared to be similar to the service users in almost all of their personal characteristics. However, they had a significantly lower awareness of the existing service agencies than did the service users $(p<.007)$, causing them more difficulties when seeking formal help. Compared with the other two groups of non-users, these non-users were less educated (12.3 and 11.0 vs. 10.6 years of schooling) and had lived in Canada for a shorter period (11.1 and 14.8 vs. 10.3 years of residency). These personal characteristics could directly weaken the non-users' personal competence and indirectly hinder their adaptation to the host society.

(Table 4 about here)

\section{Discussion}

The findings of the present study confirm those reported by previous studies: that awareness of service agencies and positive opinions about the services provided are power predictors of Chinese Canadians' use of social services. In addition, in this study, education level is an effective predisposing factor for the act of seeking help, though it explains only a small portion of the variance of Chinese Canadians' service utilization. Interestingly, education level and 
awareness of service agencies were also found to be effective factors in differentiating service users from non-users among Chinese Canadians.

Of all the predictors identified in the regression analyses, awareness of service agencies is the most powerful in terms of explaining Chinese Canadians' use of social services. This explanatory power remains intact even controlling for socio-demographic characteristics. In other words, the social services used by Chinese Canadians vary with their knowledge of services, regardless of their personal backgrounds. Here lies a significant implication: that in order to facilitate the adaptation of immigrants of ethnic minorities to the host society, the existence of available support services should be made known to those in need as far as possible, by culturally appropriate social marketing strategies.

Knowledge of services does not necessarily lead to service use per se, as the decision to seek formal assistance is also affected by the potential users' opinions on the services provided (Cho, 1998). It must be said though, that many Chinese immigrants are reluctant to seek help from outsiders, especially those representing formal organizations. Traditionally, Chinese people do not want to disclose their family problems, nor rely on social welfare. Furthermore, they are often unfamiliar with the differences between social welfare and social services. As such, proven culturally-responsive means should be employed to clarify the nature of formal support services and the citizens' rights to use such services.

The appropriateness and acceptability of the available services also influence the way in which the potential service users seek help (Damron-Rodriguez et al., 1994; Wallace, 1990). In this study, the "self-reliant" non-users would not choose to solve their problems by themselves, if appropriate services were available to them. This speculation is partly supported by the finding that some of the non-users who encountered difficulty in obtaining formal help complained that the 
services they needed did not exist. Since a considerable number of these non-users were long-time Canadian residents, the service agencies should provide them with services different from those that are provided for newcomers, in order to better facilitate their adaptation of these 'old-timers' to Canadian society.

As discussed in the former sections, those non-users who could not obtain the formal support they needed appear to be the most unfortunate group among the subjects of this study. Despite the relatively small size of this group, their service needs should be given a much higher priority by service providers. In order to facilitate their adaptation to Canadian society, service providers should improve the accessibility of available services by taking effective measures to remove structural barriers to such services. Since a majority of the Chinese Canadian community members are willing to support these services through voluntary work or donations (Ma, 1996), service providers could mobilize these resources to further develop and improve existing services to meet the unmet needs of these underprivileged people.

\section{Conclusions}

The analysis and discussion above are based on information derived from an existing data set, in which some data essential to examining the behavior of people seeking help - such as human capital, the existence of informal support networks, indicators of need for services, and immigration experiences - were not available. These shortcomings confine the scope of the present study and could adversely affect its findings.

Nevertheless, the findings of this study strongly imply that when planning services for an ethnic minority group like Chinese Canadians, planners should consider socio-cultural and structural factors alike. The resulting improvement in the availability and accessibility of services 
would certainly facilitate service utilization by ethnic minorities, even though their socio-cultural backgrounds would largely determine the way in which they seek help. Service providers should make it a priority to target the most socially vulnerable service users and those potential users needing culturally-sensitive services, the type and intensity of which should be consonant with their needs.

These findings could also be applied to Chinese emigrant communities in Asia or other continents, despite the aforementioned limitations and the Canadian context of the data collected. Nevertheless, further studies on the use of and barriers to services for Chinese immigrants in other societal context are warranted. In order to gain a better understanding of the different help-seeking behavior of service users and potential users, the acquisition of adequately large population samples and of important data on service needs, informal support networks, household incomes, and attitudes toward use of formal services is essential.

Following these suggestions could help enhance the appropriateness, accessibility, and acceptability of the services for ethnic minority groups, and contribute to the understanding of human service utilization.

\section{AUTHOR'S NOTE:}

The authors would like to acknowledge the financial support to this study by the Trillium Foundation, Ontario, Canada. Gratitude is also extended to the Task Force on Sustenance and Transformation of Agencies Serving the Chinese Canadian Community, Toronto, Ontario, Canada for its technical support during the data collection. 


\section{TABLES}

Table 1: Major Characteristics of the Respondents

\begin{tabular}{|c|c|c|}
\hline Personal Characteristics & Percentage & $N$ \\
\hline \multicolumn{3}{|c|}{ Age } \\
\hline Under 20 & 2.9 & 8 \\
\hline $20-29$ & 16.5 & 46 \\
\hline $30-39$ & 27.6 & 77 \\
\hline $40-49$ & 20.1 & 56 \\
\hline $50-59$ & 10.0 & 28 \\
\hline 60 and over & 22.9 & 64 \\
\hline \multicolumn{3}{|c|}{ Gender } \\
\hline Female & 49.8 & 139 \\
\hline Male & 50.2 & 140 \\
\hline \multicolumn{3}{|c|}{ Education Level } \\
\hline No formal education & 2.2 & 6 \\
\hline Elementary school & 13.3 & 37 \\
\hline High school & 39.4 & 110 \\
\hline Post-secondary school & 15.1 & 42 \\
\hline University & 25.8 & 72 \\
\hline Postgraduate school & 4.3 & 12 \\
\hline \multicolumn{3}{|c|}{ Place of Origin } \\
\hline Hong Kong & 73.4 & 205 \\
\hline Mainland China & 14.7 & 41 \\
\hline Indo-China & 5.0 & 14 \\
\hline Taiwan & 3.6 & 10 \\
\hline Other & 3.2 & 9 \\
\hline \multicolumn{3}{|c|}{ Length of Residency } \\
\hline Under 5 years & 26.5 & 74 \\
\hline $5-9$ years & 31.5 & 88 \\
\hline 10 - 19 years & 26.9 & 75 \\
\hline 20 - 29 years & 9.7 & 27 \\
\hline 30 - 39 years & 2.5 & 7 \\
\hline 40 years and over & 2.9 & 8 \\
\hline
\end{tabular}


Table 2: Regression Analysis of the Amount of Use of Social Services among Chinese Canadians

\begin{tabular}{lcc}
\hline Factors & Model 1 & Model 2 \\
\hline Intercept & $1.997^{\mathrm{a}}$ & -.156 \\
Predisposing Factors & & \\
$\quad$ Age & $.011^{\mathrm{b}}$ & -.072 \\
$\quad$ Gender & -.019 & -.002 \\
$\quad$ Education level & $-.131^{* *}$ & $-.111^{*}$ \\
Length of residency & -.003 & -.029 \\
Facilitating Factors & & \\
Awareness of agencies & & $.240^{* * *}$ \\
Opinion on services & & $.166^{* * *}$ \\
Ability to differentiate & & \\
$\quad \begin{array}{l}\text { social services from } \\
\text { social security programs }\end{array}$ & & -.061 \\
F-ratio & & 4.598 \\
Total $R^{2}$ & .024 & .106 \\
\hline
\end{tabular}

${ }^{\mathrm{a}}$ Unstandardized Regression Coefficient

${ }^{\mathrm{b}}$ Standardized Regression Coefficient

$*=p<.10 * *=p<.05 \quad * * *=<.01$ 
Table 3: Reasons for Not-Using any Social Services

\begin{tabular}{|c|c|c|}
\hline Reasons & Frequency & Percent \\
\hline Don’t need such services & 40 & 43.9 \\
\hline Want to solve own problems by oneself & 19 & 20.9 \\
\hline Don't know where the services are available & 13 & 14.3 \\
\hline Location of agencies is not easily accessible & 7 & 7.7 \\
\hline Application procedures are complicated & 5 & 5.5 \\
\hline Services needed are not available & 4 & 4.3 \\
\hline Waiting list is too long & 3 & 3.3 \\
\hline Total & 91 & 100.0 \\
\hline
\end{tabular}


Table 4: Comparison of Characteristics between users and non-users of social services

\begin{tabular}{|c|c|c|c|c|c|c|c|}
\hline \multirow[b]{2}{*}{$\begin{array}{l}\text { Personal } \\
\text { Characteristics }\end{array}$} & \multirow[b]{2}{*}{$\begin{array}{l}\text { Service } \\
\text { Users } \\
(n=188)\end{array}$} & \multicolumn{3}{|c|}{$\frac{\text { Non-Users }}{\text { Self }}$} & \multicolumn{3}{|c|}{$\frac{\text { ANOVA p-value }}{\text { Users }}$} \\
\hline & & $\begin{array}{c}\text { No Need } \\
(n=40)\end{array}$ & $\begin{array}{c}\text { Self } \\
\text { Reliant } \\
(n=19)\end{array}$ & $\begin{array}{l}\text { Others } \\
(n=32)\end{array}$ & $\begin{array}{l}\text { Users \& } \\
\text { No Need }\end{array}$ & $\begin{array}{l}\text { Users } \\
\text { \& Self } \\
\text { Reliant }\end{array}$ & $\begin{array}{l}\text { Users \& } \\
\text { Others }\end{array}$ \\
\hline Mean age & 37.70 & 36.10 & 41.30 & 36.90 & .408 & .362 & .765 \\
\hline Sex ratio & 1: 0.90 & 1:1.18 & $1: 1.32$ & $1: 1.10$ & .094 & .061 & .409 \\
\hline Mean education level in years & 8.90 & 12.30 & 11.0 & 10.60 & .001 & .149 & .212 \\
\hline Mean length of residency in years & 9.69 & 11.06 & 14.81 & 10.29 & .273 & .004 & .717 \\
\hline Awareness of agencies $(1-7)^{\mathrm{a}}$ & 3.63 & 2.90 & 3.03 & 2.77 & .003 & .068 & .007 \\
\hline Opinion on services $(1-5)$ & 4.29 & 4.15 & 4.15 & 4.24 & .120 & .244 & .659 \\
\hline $\begin{array}{l}\text { Ability to differentiate } \\
\text { social services from social } \\
\text { security programs }(0-3)\end{array}$ & 2.41 & 2.46 & 2.31 & 2.16 & .704 & .564 & .144 \\
\hline
\end{tabular}

${ }^{a}$ Values in brackets indicate the minimum and maximum of each variable. 


\section{REFERENCES}

Andersen, R.M., and Newman, J.F. (1973). Societal and individual determinants of medical care utilization in the U.S. Milbank Memorial Fund Quarterly, 51, 95-124.

Auslander, G.K. \& Litwin, H. (1990). Social support networks and formal help seeking: Differences between applicants to social services and a nonapplicant sample. Journal of Gerontology, 45 (3): 5112-5119.

Bass, D.M., Looman, W.J. and Ehrlich, P. (1992). Predicting the volume of health and social services: Integrating cognitive impairment into the modified Andersen framework. The Gerontologist, 32, 3343.

Biegel, D.E., Farkas, K.J., Song, L. (1997). Barriers to the use of mental health services by AfricanAmerican and Hispanic elderly persons. Journal of Gerontological Social Work, 29(1): 23-44.

Carlton-LaNey, Iris (1991). Some consideration of the rural elderly black's underuse of social services. Journal of Gerontological Social Work, 16 (1-2): 3-17.

Cho, P.J. (1998). Awareness and utilization: A Comment. The Gerontologist, 38(3): 317-379.

Damron-Rodriguez, J., Wallace, S.P., \& Kington, R. (1994). Service utilization and minority elderly: Appropriateness, accessibility and acceptability. Gerontology and Geriatrics Education, 15(1): 4563.

Keller, JoDee \& McDade, Katherine (1997). Cultural diversity and help-seeking behavior: Sources of help and obstacles to support for parents. Journal of Multicultural Social Work, 5(1/2): 63-78.

Kuo, T. \& Torres-Gil, F.M. (2001). Factors affecting utilization of health services and home- and community-based care programs by older Taiwanese in the United States. Research on Aging, 23(1): $12-36$. 
Lum, Y-S. \& Chang, H-J. (2000). The effect of Medicaid coverage on use of health service by low-income elderly people. In Sharon M. Keigher, Fortune, Anne E., Stanley Witkin (Ed.), Aging and Social Work: The Changing Landscapes, Washington: NASW Press.

Ma, Ambrose (1996). The Chinese Canadian Perception of Community and Social Services: A Survey

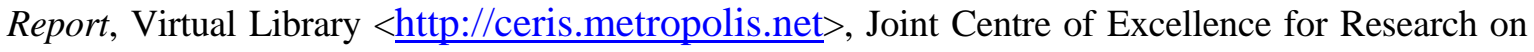
Immigration and Settlement, Toronto, Ontario, Canada.

Miner, S., Logan, J.R., and Spitze, G. (1993). Predicting the frequency of senior center attendance. The Gerontologist, 33 (5): 650-657.

Moon, A., Lubben, J.E., \& Villa, V. (1998). Awareness and utilization of community long-term care services by elderly Korean and non-Hispanic White Americans. The Gerontologist, 38(3): 309-316.

O'Donnell, Julie, \& Giovannoni, Jeanne M. (1999). Ethnic differences in service, preferences, and service delivery aspects among consumers and potential consumers of family resource centers. Journal of Multicultural Social Work, 7(3/4): 1-18.

Paulino, Ana (1998). Dominican immigrant elders: Social service needs, utilization patterns, and challenges. Journal of Gerontological Social Work, 30(1/2): 61-74.

Slivinske, L.R., Fitch, V.L., \& Mosca, J. (1994). Predicting health and social service utilization of older adults. Journal of Social Services Research, 20(2): 21-40.

Snowden, L.R. and Cheung, F.K. (1990). Use of inpatient mental health services by members of ethnic minority groups. American Psychologist, 45, 347-355.

Sowers, Hoag, K.M. and Siddharthan, K. (1992). Access and use of health related social services of immigrants and native born Americans: Implications for social interventions. Journal of Multicultural Social Work, 1 (4): 47-61.

Starrett, R.A., Rogers, D., \& Decker, J.T. (1992). The self-reliance behavior of the Hispanic elderly in comparison to their use of formal mental health help network. Clinical Gerontologist, 11(4): 157169. 
Sue, S., Fujino, D., Hu, L., Takeuchi, D.T., Zane, N.W. (1991). Community mental health services for ethnic minority groups: A test of the cultural responsiveness hypothesis. Journal of Consulting and Clinical Psychology, 59, 533-540.

Tanjasiri, S.P., Wallace, S.P., \& Shibata, K. (1995). Picture imperfect: Hidden problems among Asian Pacific Islander elderly. The Gerontologist, 35(6): 753-760.

Tang, K.C. (1996). Utilization of medical services-difficulties and solutions: A case study of Chinese Australian in Sydney. Journal of Multicultural Social Work, 4(2): 47-58.

Tsai, D.T. \& Lopex, R.A. (1997). The use of social supports by elderly Chinese immigrants. Journal of Gerontological Social Work, 29(1): 77-94.

Wallace, Steven P. (1994). Structural barriers to the use of formal in-home services by older Hispanic Americans. Journal of Gerontology, 49(5): S253.

Wallace, Steven P. (1990). The no-care zone: Availability, accessibility and acceptability in communitybased long-term care. The Gerontologist, 30(2): 254-261.

Wolinsky, Fredric D. and Johnson, Robert J. (1991). The use of health service by older adults. Journal of Gerontology: Social Sciences, 46 (6): S 345-357.

Yeatts, Dale E., Crow, Thomas, and Folts, Edward (1992). Service use among low-income minority elderly: strategies for overcoming barriers. The Gerontologist, 32 (1): 24-32.

Ying, Yu-Wen and Miller, Leonard S. (1992). Help-seeking behavior and attitude of Chinese Americans regarding psychological problems. American Journal of Community Psychology, Vol. 20, No. 4, 549-556. 